\title{
Genetic evidence against the 165 ribosomal RNA helix 27 conformational switch model
}

\author{
DANIEL RODRIGUEZ-CORREA and ALBERT E. DAHLBERG
}

Department of Molecular Biology, Cell Biology and Biochemistry, Brown University, Providence, Rhode Island 02912, USA

\begin{abstract}
A mechanistic understanding of ribosome function demands knowledge of the conformational changes that occur during protein synthesis. One current model proposes a conformational switch in Helix 27 (H27) of 165 rRNA involved in the decoding of mRNA. This model was based on the behavior of mutations in the 912 region of $\mathrm{H} 27$ of Escherichia coli 16S rRNA, which were predicted to stabilize the helix in either of two alternative conformations. This interpretation was supported by evidence from both genetics and structural biochemistry. However, recently published X-ray crystallographic structures of the Thermus thermophilus 30S subunit at different stages of tRNA selection have raised doubts regarding the validity of this model. We have therefore revisited the model genetically by constructing a $\mathrm{H} 27$ quadruple mutation (C912G, C910G, G885C, and G887C), which would create multiple mismatches in the proposed alternative conformation without perturbing the native $\mathrm{H} 27$ conformation seen in the crystal structures. Inconsistent with the $\mathrm{H} 27$ switch model, cells containing pure populations of quadruple mutant ribosomes grow at essentially wild-type rates. The mutants used to construct the $\mathrm{H} 27$ switch model all carried A2058G in $23 S$ rRNA and $\mathrm{C} 1192 \mathrm{U}$ in $16 \mathrm{~S}$ rRNA as selectable markers. The quadruple mutant carrying these additional marker mutations is deleterious, and we conclude that they have a synergistic effect when combined with other mutations and are not phenotypically silent. Their presence confounded the interpretation of the original mutant phenotypes and, in light of the viability of the quadruple mutant, we conclude that the genetic evidence no longer supports the model.
\end{abstract}

Keywords: Helix 27 switch model; translational accuracy; S5 ram mutation; C1192U mutation; A2058G mutation; 16S ribosomal RNA

\section{INTRODUCTION}

A driving force in ribosome research has been the concept of the ribosome as a complex protein synthesis machine able to undergo strictly coordinated movements during translation. Various models for conformational changes during ribosome function have been proposed (Glotz and Brimacombe 1980; Sigmund et al. 1984; Lodmell and Dahlberg 1997; Ogle et al. 2001, 2002; Spirin 2002). One of the first models proposing specific conformational changes associated with accurate tRNA selection involved a triplet base-pair switch in the 912 region of helix 27 (H27) of $16 \mathrm{~S}$ rRNA (Lodmell and Dahlberg 1997).

The H27 switch model states that this helix exists in a dynamic equilibrium between two conformational states (Lodmell and Dahlberg 1997). The model was based on the

Reprint requests to: Albert E. Dahlberg, Department of Molecular Biology, Cell Biology and Biochemistry, Brown University, Providence, RI 02912, USA; e-mail: Albert_Dahlberg@brown.edu; fax: (401) 863-1182.

Article and publication are at http://www.rnajournal.org/cgi/doi/ 10.1261/rna.5172104. phenotypes of mutations in Escherichia coli $16 \mathrm{~S}$ rRNA that were predicted to affect the stability of these two states, termed the 912-885 and 912-888 conformations, in reference to the pairing configuration of these bases (Fig. 1A). The 912-885 conformation was called "error prone," by analogy to ram (ribosomal ambiguity) mutations in ribosomal proteins $\mathrm{S} \overline{4}$ and $\mathrm{S} 5$, because mutations predicted to favor it produced a higher rate of reading through in-frame stop codons and possessed higher tRNA affinity. The 912888 conformation was called "restrictive" or hyperaccurate, by analogy with restrictive mutations affecting ribosomal protein S12, because mutations predicted to favor this conformation restricted suppression of stop codons and had lower A-site tRNA affinity. A direct participation of these ribosomal proteins in the switch was suggested by their phenotypic similarity to the rRNA mutations. Further, mutations predicted to favor the 912-885 conformation were not compatible with S5 ram mutations but were compatible with $\mathrm{S} 12$ restrictive mutants, and those predicted to favor the 912-888 conformation were only compatible with S5 ram mutations, suggesting that the rRNA and ribosomal 
A.

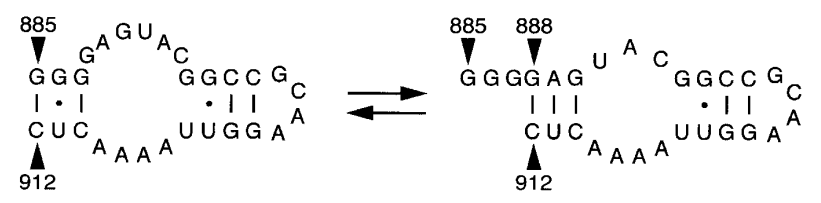

B.

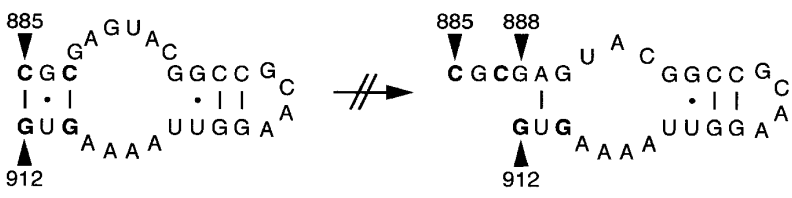

FIGURE 1. The H27 conformational switch model. (A) The two proposed conformations, 912-885 (left) and 912-888 (right), in H27 of wild-type $16 \mathrm{~S}$ rRNA. (B) The quadruple mutation retains the WatsonCrick pairing configuration of the 912-885 conformation while preventing the formation of the alternative $912-888$ pairing.

protein mutations interacted. Because of all these various effects on fidelity, it was suggested that the H27 conformational switch was involved in the decoding process (Lodmell and Dahlberg 1997). Specifically, it was proposed that ribosomes increased the stringency of tRNA selection in the A site by transiently adopting the $912-888$ conformation, thus allowing noncognate tRNAs to dissociate.

Mutations in $\mathrm{H} 27$ were observed to affect the reactivity of a number of bases in the $30 \mathrm{~S}$ subunit to base-specific chemical probes, suggesting conformational effects beyond the immediate vicinity of H27 (Lodmell and Dahlberg 1997). Evidence of effects on both subunits of the $70 \mathrm{~S}$ ribosome structure were provided by cryo-electron microscopic reconstructions of $70 \mathrm{~S}$ ribosomes containing mutations in H27 (Gabashvili et al. 1999). The structural changes observed were mainly in the A-site tRNA binding region on the $30 \mathrm{~S}$ subunit, lending an explanation for the changes in tRNA affinity and the effects on accuracy caused by these mutations.

Despite the general enthusiasm enjoyed for the H27 switch model, more recent evidence has raised doubts regarding the occurrence of this conformational switch during decoding. Studies in yeast ribosomes did not support the conformational switch model when it was found that mutations in the equivalent region predicted to increase the translational error frequency had, in fact, the opposite effect (Velichutina et al. 2000). Various high-resolution structures of native and antibiotic-bound $30 \mathrm{~S}$ subunits of Thermus thermophilus have been solved (Carter et al. 2000; Schluenzen et al. 2000; Wimberly et al. 2000) and the base-pairing arrangement of $\mathrm{H} 27$ observed in these structures has uniformly been that of the 912-885 conformation. The alternative $912-888$ conformation has also not been observed in
X-ray structures of intact 70S ribosomes (Yusupov et al. 2001).

According to the $\mathrm{H} 27$ switch model, a mutation in ribosomal protein S12 that confers a hyperaccurate phenotype, such as streptomycin dependence, should stabilize the 912888 base-pairing configuration of H27. Recently, a $9 \AA$ Xray crystal structure of ribosomes from a streptomycindependent mutant of $E$. coli was solved (Vila-Sanjurjo et al. 2003). This structure did not show the large changes in H27 conformation predicted by the switch model. Equally, an atomic resolution X-ray structure of a streptomycin-dependent $30 \mathrm{~S}$ subunit from $T$. thermophilus also showed $\mathrm{H} 27$ to be in the 912-885 conformation (Carter 2002). Once again, the 912-888 conformation has remained elusive, suggesting that a conformational switch in $\mathrm{H} 27$ may not be involved in decoding.

Insights into the mechanisms involved in translational fidelity and tRNA selection have recently emerged from atomic-level structural studies. It was observed that cognate tRNA binding induces conformational changes of residues A1492, A1493, and G530 of 16S rRNA (Ogle et al. 2001). These conformational changes have been proposed to function in sensing the Watson-Crick base-pairing geometry between tRNA and mRNA, and discriminate against nearcognate tRNA binding. tRNA selection has also been shown to be accompanied by a transition from an open to a closed global conformation of the $30 \mathrm{~S}$ subunit (Ogle et al. 2002). The closed conformation occurs when cognate tRNA is present in the A-site and is not achieved in the presence of near-cognate tRNA. These studies concluded that the stabilization of the closed conformation is required for tRNA selection, and may also be involved in driving the forward reactions of tRNA selection (Ogle et al. 2003). In neither the open nor the closed conformation is the 912-888 configuration of $\mathrm{H} 27$ observed.

In light of the absence of support for the H27 switch by direct visualization of the 912-888 structure, we decided to test the model by further genetic analysis. After careful examination of the $\mathrm{H} 27$ conformation from the available Xray crystallographic data, we predicted that base changes C912G, C910G, G885C, and G887C would be sufficient to prevent the formation of the proposed 912-888 conformation but with minimal disruption of the native 912-885 structure (Fig. 1B). This mutant provides a more stringent test of the model than any previously constructed and allowed us to determine if the 912-888 conformation, as proposed by the $\mathrm{H} 27$ switch model, is a necessary and functional structure of the ribosome during protein synthesis.

Here, we present evidence that the 912-888 base-paired state of the proposed $\mathrm{H} 27$ conformational switch is not necessary for ribosomal function at any stage of translation. Further, we discuss the contribution of the antibiotic marker mutations (C1192U in 16S; A2058G in 23S), previously assumed to be silent, to the behavior of the original mutants used to generate the switch hypothesis. 


\section{RESULTS AND DISCUSSION}

\section{Effect of the $\mathrm{H} 27$ quadruple mutant plasmid in a strain lacking all seven chromosomal rRNA operons}

We examined the published X-ray crystallographic structures of the 30S subunit (Carter et al. 2000; Wimberly et al. 2000) to determine the minimum required changes that could be constructed within $\mathrm{H} 27$ of $16 \mathrm{~S}$ rRNA, which would disrupt or prevent the formation of the 912-888 conformation without perturbing the Watson-Crick pairing configuration of the $912-885$ conformation. A ribosomal mutant unable to switch into the alternative 912-888 conformation should not be capable of protein synthesis if this conformation is an essential functional state of the ribosome. C912G, C910G, G885C, and G887C mutations will introduce crucial mismatches in the putative $912-888$ conformation (Fig. 1B).

As a crucial test of the $\mathrm{H} 27$ switch model, the ability of a derivative of plasmid pKK3535 bearing the quadruple mutation in the $r r n \mathrm{~B}$ operon (hereafter referred to as pQuad) to support growth as the sole source of rRNA was assessed. This was carried out using a strain $(\Delta 7 \mathrm{rrn})$ in which all seven chromosomal $\mathrm{rrn}$ operons have been deleted, and in which all rRNA is synthesized from a wild-type resident plasmid (Asai et al. 1999; Vila-Sanjurjo et al. 1999). Displacement of the resident plasmid by an incoming plasmid carrying a mutant $r r n$ operon results in the production of a pure population of mutant ribosomes. The plasmid pQuad was therefore tested for its ability to displace the wild-type resident $\mathrm{rrn}$ plasmid. Contrary to predictions made by the H27 switch model, pQuad effectively displaced the resident plasmid. Primer extension of total RNA extracted from these cells confirmed the presence of only mutant rRNA
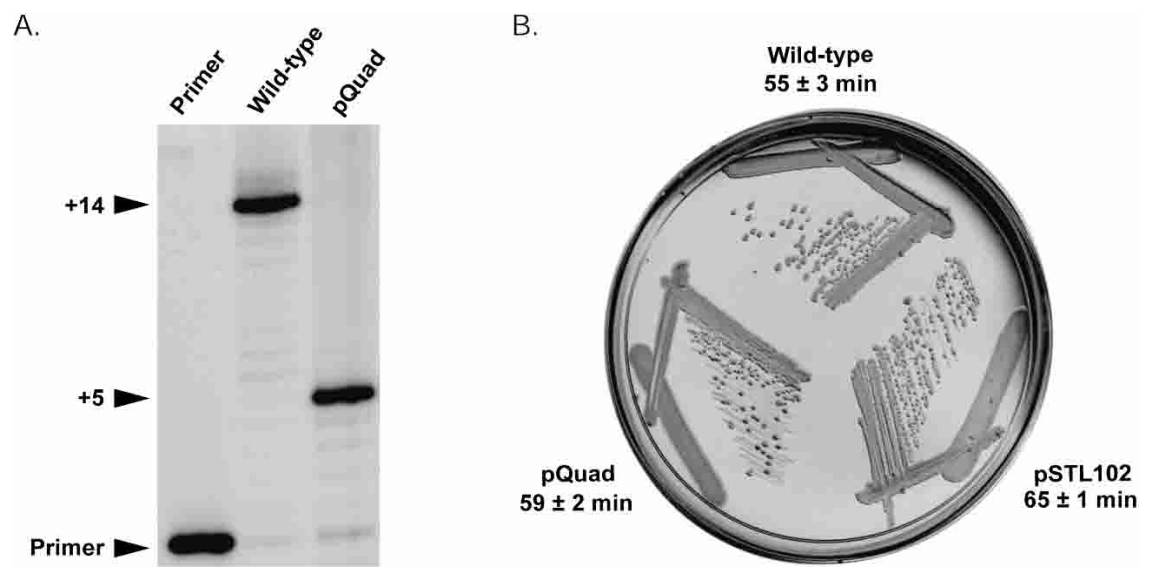

FIGURE 2. (A) Primer extension analysis of total RNA from the $\Delta 7 \mathrm{rrn}$ strain carrying either wild-type (pKK3535) or the quadruple $\mathrm{H} 27$ mutant (pQuad) plasmid. The positions +14 (G903) of wild-type RNA and +5 (C912G) of mutant RNA are indicated, confirming that pQuad could displace pKK3535. (B) Growth and doubling times for the $\Delta 7 \mathrm{rrn}$ strain containing wild-type plasmid (pKK3535), the quadruple mutant plasmid (pQuad) and plasmid pSTL102 with ribosomal selectable marker mutations C1192U and A2058G.
(Fig. 2A). Remarkably, introduction of pQuad barely increased the doubling time of the $\Delta 7 \mathrm{rrn}$ strain, from 55 to 59 min, indicating that the mutant ribosomes are fully capable of providing all the cell's protein synthesis requirements (Fig. 2B).

\section{Effects of additional selectable marker mutations}

In the original study (Lodmell and Dahlberg 1997), mutations had been introduced into plasmid pSTL102 that bears the $\mathrm{C} 1192 \mathrm{U}$ spectinomycin-resistance mutation in the $16 \mathrm{~S}$ rRNA gene and the A2058G erythromycin-resistance mutation in the $23 \mathrm{~S}$ rRNA gene. These mutations provided selectable markers to facilitate the genetic manipulation of the $r r \mathrm{~B}$ operon. Thus, for direct comparison with the original model, the same quadruple mutation in $\mathrm{H} 27$ was also introduced into plasmid pSTL102.

Although a plasmid containing only the mutations C1192U and A2058G was able to displace the resident wildtype plasmid, the plasmid construct containing the $\mathrm{H} 27$ quadruple mutation combined with mutations $\mathrm{C} 1192 \mathrm{U}$ and A2058G was not able to displace. The C1192U and A2058G mutations alone increased the doubling time of the $\Delta 7 \mathrm{rrn}$ strain to $65 \mathrm{~min}$, a greater effect on growth than the quadruple mutation in $\mathrm{H} 27$. Thus, there appears to be a profound phenotypic interaction between the $\mathrm{H} 27$ mutations and either or both of these antibiotic-resistance mutations.

\section{Viability of an S5 mutant strain containing the $\mathrm{H} 27$ quadruple mutation}

A further test of the model is that rRNA mutations predicted to favor the 912-885 conformation and to destabilize the 912-888 conformation should not be compatible with protein S5 ram mutations. Accordingly, pQuad was introduced into the S5 ram strain, UD11F7, used in the original H27 switch study (Lodmell and Dahlberg 1997). Growth of UD11F7 carrying pQuad was not retarded compared to wild-type (as judged by colony formation), in fundamental contradiction of the switch model.

The plasmid combining the quadruple $\mathrm{H} 27$ mutation with the $\mathrm{C} 1192 \mathrm{U}$ and A2058G mutations was also introduced into UD11F7. No growth was observed in this case. These results are in agreement with those obtained previously in which the double mutation C912G, G885C was unstable in UD11F7, and the double mutation C910G, G887C was lethal in this strain (Lodmell and Dahlberg 1997). The only difference between these double mu- 
tants and the pQuad mutant, apart from the combination of the $\mathrm{H} 27$ mutations, is the presence of the selectable marker mutations C1192U and A2058G, suggesting once again that these mutations have a synergistically deleterious effect on ribosome function.

There has been a general assumption that C1192U and A2058G are silent, and these mutations had been widely used as selectable markers for the isolation of mutants with detectable phenotypes prior to the development of the $\Delta 7$ rrn strain (Triman et al. 1989; Powers and Noller 1990; Lodmell et al. 1995; Rosendahl et al. 1995). The results presented here indicate that the incompatibility of the H27 and r-protein mutations seen in the original study (Lodmell and Dahlberg 1997) was influenced by the presence of these two mutations. Ribosomes, which carry either the quadruple mutation or the two antibiotic-resistance mutations, are able to support cell growth without the presence of wild-type ribosomes. It is only in a mutant combining the quadruple mutations of $\mathrm{H} 27$ with the selectable marker mutations C1192U and A2058G that functional defects and incompatibility with S5 ram mutations are observed. The C1192U mutation has also been observed to produce anomalous effects in combination with a mutation in $\mathrm{H} 44$ (Recht and Puglisi 2001). Additionally, the combination of the C1192U and A2058G mutations suppresses a temperature-sensitive mutation in EF-G (Koosha et al. 2000).

It is now evident from the $30 \mathrm{~S}$ subunit crystal structures that the UD11F7 ram mutant in ribosomal protein S5 is located at the interface between S5 and S4, as indeed are other ram mutations (Brodersen et al. 2002; Ogle et al. 2002). In light of the $\mathrm{H} 27$ switch model, the lack of an effect of S4 ram mutations upon the growth characteristics described for the original "restrictive" H27 mutations (Lodmell and Dahlberg 1997) is, therefore, curious. Importantly, however, S5 contacts H34 near the site of residue 1192, so the spectinomycin-resistance mutation C1192U may be predicted to have effects on S5 which, through $\mathrm{H} 1$, affect $\mathrm{H} 27$ (Fig. 3B). It is perhaps not a coincidence then, that $\mathrm{H} 27$ "ram" mutations are incompatible only with S5 ram and not S4 ram mutations (Lodmell and Dahlberg 1997) in the presence of the C1192U mutation.

\section{Concluding remarks}

$\mathrm{H} 27$ is involved in the formation of a complex junction that organizes the $5^{\prime}$ and central domains of $16 \mathrm{~S}$ rRNA (Masquida et al. 1997). The helix is packed against the minor groove of a helical stack made up of $\mathrm{H} 1$ and H28 (Wimberly et al. 2000), the 900 region tetraloop is involved in RNARNA interactions with $\mathrm{H} 24$ of $16 \mathrm{~S}$ rRNA (Belanger et al. 2002), and the universally conserved nucleotides 889-892/ 907-909 comprise an E-loop motif in H27 (Leontis and Westhof 1998). The X-ray crystal structure of the 30S subunit reveals how these elements of $\mathrm{H} 27$ combine to form a tightly packed structure (Fig. 3A) with an extensive network
A



B

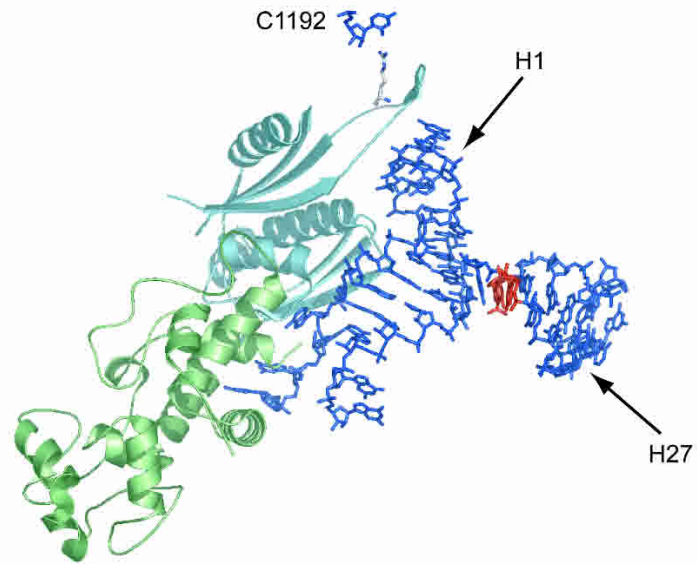

FIGURE 3. (A) Extensive packing of $\mathrm{H} 27$ with components of the decoding region, as viewed from the subunit interface. 16S rRNA helices 1, 24, 44 (blue) abut H27 (hot pink) with proteins S5 (cyan) and S12 (orange). H28 is omitted for clarity. (B) Residue 1192 within H34 in close proximity to ribosomal protein S5. C912-G885 base pair (red), 16S rRNA helices 1 and 27 (blue), proteins S5 (cyan) and S4 (green). Structures rendered using PyMOL molecular system software (DeLano 2002), and PDB file 1J5E (Wimberly et al. 2000).

of hydrogen bonds (Wimberly et al. 2000). The structure also reveals interactions of $\mathrm{H} 27$ with ribosomal protein S12 and $\mathrm{H} 44$ that have been shown to be involved in the closing and opening dynamics of the $30 \mathrm{~S}$ subunit during tRNA selection (Ogle et al. 2002). All of these structural elements are present in the highly conserved decoding center of the 30 S ribosomal subunit. A transition between the 912-885 and 912-888 conformations would therefore require the disruption of a large number of higher order interactions in addition to the base-pairing interactions directly implicated in the model. This complex network of RNA-RNA and RNA-protein interactions only became evident after the $\mathrm{X}$-ray crystal structure of the $30 \mathrm{~S}$ subunit was solved. 
The evidence presented here clearly implies that the alternative 912-888 conformation of the H27 conformational switch is not a functional structure, and that ribosomes do not adopt this alternative structure during protein synthesis. Although formally it is not possible to exclude the presence of this conformation absolutely, and we are certainly not suggesting that there is no movement in this region (VanLoock et al. 2000; Tama et al. 2003), we conclude that the specific base-pairing arrangement of the switch model does not occur. The evidence also shows that the observations from which the model was proposed were influenced by the selectable marker mutations present on the ribosomes.

Nevertheless, the $\mathrm{H} 27$ switch was an attractive model at a time when no high-resolution X-ray crystallographic structures of the ribosome were available, and its lasting contribution may well be that it reinforced the notion that the ribosome might undergo switch-like conformational changes at each of the steps of protein synthesis. Such thinking has proven fruitful in exploring details of tRNA selection (Ogle et al. 2001, 2002) and, at lower resolution (Agrawal et al. 1999; Frank and Agrawal 2000; Wriggers et al. 2000; Frank and Agrawal 2001; Valle et al. 2002, 2003), in modeling the changes undergone by ribosomes and translational factors during the elongation cycle.

\section{MATERIALS AND METHODS}

\section{Bacterial strains and plasmids}

The plasmids pKK3535 (Brosius et al. 1981) and pSTL102 (Triman et al. 1989) were used as rRNA expression vectors. Plasmid pKK3535 contains an intact wild-type $r r n \mathrm{~B}$ operon and plasmid pSTL102 contains an $\mathrm{rrnB}$ operon with the C1192U spectinomycin-resistance mutation in the 16S rRNA gene and the A2058G erythromycin-resistance mutation in the 23S rRNA gene. Strain DH1 was transformed with the plasmids and their derivatives after mutagenesis.

Viability of mutant plasmid derivatives as a sole source of ribosomes was studied in the $\Delta 7 \mathrm{rrn}$ strain AVS $69009(\Delta r r \mathrm{E} \Delta r r n \mathrm{~B}$ $\Delta r r n \mathrm{~A} \quad \Delta r r n \mathrm{H} \quad \Delta r r \mathrm{G}::$ lacZ $\Delta r r n \mathrm{C}::$ cat $\Delta r r n \mathrm{D}::$ cat $\Delta r e c \mathrm{~A} /$ pTRNA66, pHKrrnC) (Vila-Sanjurjo et al. 1999). Plasmid replacement of the resident wild-type $r r n$ operon with a mutant $r r n$ operon was carried out as previously described (Asai et al. 1999).

Compatibility of rRNA mutations with an S5 ram mutant was tested by transferring the mutant $r r n$ plasmids into strain UD11F7 (Andersson et al. 1982; Lodmell and Dahlberg 1997), which harbors a $\mathrm{R} 112 \mathrm{C}$ mutation in the gene for ribosomal protein S5 (this work), resulting in a translational error-prone (ram) phenotype.

\section{Mutagenesis}

The H27 quadruple mutation C912G, C910G, G885C, and G887C (Fig. 1B) was constructed by site-directed mutagenesis of plasmids pKK3535 or pSTL102 using the QuickChange protocol (Strata gene) with oligonucleotide primers (5'-CGTCAATTCATTTCA
CTTTTAACCTTGCGGCCGTACTCGCGAGGCGGTCGAC-3') and (5'-GTCGACCGCCTCGCGAGTACGGCCGCAAGGTTAAAA GTGAAATGAATTGACG-3'). The presence of the mutations was confirmed by sequencing.

\section{Total RNA primer extension}

Total RNA was extracted from cells and primer extension, to distinguish wild-type from mutant RNA, was carried out as described (Sigmund et al. 1988), using oligonucleotide primer 912RT (5' GCGGGCCCCCGTCAATTC-3') complementary to positions C917-C934 of 16S rRNA and dATP, dGTP, dTTP, and ddCTP for both wild-type and mutant RNA. A strong stop position at +14 represents wild-type RNA and that at +5 indicates the mutant.

\section{Growth rates}

Single colonies of AVS69009 containing wild-type or mutant $r r n$ operon plasmids were picked directly into liquid LB medium containing $200 \mu \mathrm{g} / \mathrm{mL}$ ampicillin and grown to saturation at $37^{\circ} \mathrm{C}$. Growth rates were monitored following a 1:100 dilution into 15 $\mathrm{mL}$ of the same medium using a Klett-Summerson colorimeter.

\section{ACKNOWLEDGMENTS}

We thank all the members of our laboratory, especially Jill Thompson and Steven Gregory, for their unparalleled support, discussions, and critical review of the manuscript. We thank Venki Ramakrishnan, Steve Lodmell, and Michael O'Connor for their comments and suggestions. This research was supported by a grant from the U.S. National Institutes of Health GM19756 (to A.E.D) and a Ruth Kirschstein MARC Predoctoral Fellowship Award (to D.R.-C.).

The publication costs of this article were defrayed in part by payment of page charges. This article must therefore be hereby marked "advertisement" in accordance with 18 USC section 1734 solely to indicate this fact.

Received August 29, 2003; accepted September 29, 2003.

\section{REFERENCES}

Agrawal, R.K., Heagle, A.B., Penczek, P., Grassucci, R.A., and Frank, J. 1999. EF-G-dependent GTP hydrolysis induces translocation accompanied by large conformational changes in the $70 \mathrm{~S}$ ribosome. Nat. Struct. Biol. 6: 643-647.

Andersson, D.I., Bohman, K., Isaksson, L.A., and Kurland, C.G. 1982. Translation rates and misreading characteristics of rpsD mutants in Escherichia coli. Mol. Gen. Genet. 187: 467-472.

Asai, T., Zaporojets, D., Squires, C., and Squires, C.L. 1999. An Escherichia coli strain with all chromosomal rRNA operons inactivated: Complete exchange of rRNA genes between bacteria. Proc. Natl. Acad. Sci. 96: 1971-1976.

Belanger, F., Leger, M., Saraiya, A.A., Cunningham, P.R., and BrakierGingras, L. 2002. Functional studies of the 900 tetraloop capping helix 27 of 16S ribosomal RNA. J. Mol. Biol. 320: 979-989.

Brodersen, D.E., Clemons Jr., W.M., Carter, A.P., Wimberly, B.T., and Ramakrishnan, V. 2002. Crystal structure of the 30 S ribosomal subunit from Thermus thermophilus: Structure of the proteins and their interactions with 16S RNA. J. Mol. Biol. 316: 725-768. 
Brosius, J., Ullrich, A., Raker, M.A., Gray, A., Dull, T.J., Gutell, R.R., and Noller, H.F. 1981. Construction and fine mapping of recombinant plasmids containing the $\mathrm{rrnB}$ ribosomal RNA operon of $E$. coli. Plasmid 6: 112-118.

Carter, A.P. 2002. "Structural studies of the 30 S ribosomal subunit." Ph.D. thesis, University of Cambridge, England.

Carter, A.P., Clemons, W.M., Brodersen, D.E., Morgan-Warren, R.J., Wimberly, B.T., and Ramakrishnan, V. 2000. Functional insights from the structure of the $30 \mathrm{~S}$ ribosomal subunit and its interactions with antibiotics. Nature 407: 340-348.

DeLano, W.L. 2002. The PyMOL molecular system. DeLano Scientific, San Carlos, CA.

Frank, J. and Agrawal, R.K. 2000. A ratchet-like inter-subunit reorganization of the ribosome during translocation. Nature 406: 318 322.

- 2001. Ratchet-like movements between the two ribosomal subunits: Their implications in elongation factor recognition and tRNA translocation. Cold Spring Harb. Symp. Quant. Biol. 66: 6775.

Gabashvili, I.S., Agrawal, R.K., Grassucci, R., Squires, C.L., Dahlberg, A.E., and Frank, J. 1999. Major rearrangements in the 70S ribosomal 3D structure caused by a conformational switch in $16 \mathrm{~S}$ ribosomal RNA. EMBO J. 18: 6501-6507.

Glotz, C. and Brimacombe, R. 1980. An experimentally-derived model for the secondary structure of the 16S ribosomal RNA from Escherichia coli. Nucleic Acids Res. 8: 2377-2395.

Koosha, H., Cameron, D., Andrews, K., Dahlberg, A.E., and March, P.E. 2000. Alterations in the peptidyltransferase and decoding domains of ribosomal RNA suppress mutations in the elongation factor G gene. RNA 6: 1166-1173.

Leontis, N.B. and Westhof, E. 1998. A common motif organizes the structure of multi-helix loops in $16 \mathrm{~S}$ and $23 \mathrm{~S}$ ribosomal RNAs. J. Mol. Biol. 283: 571-583.

Lodmell, J.S. and Dahlberg, A.E. 1997. A conformational switch in Escherichia coli 16S ribosomal RNA during decoding of messenger RNA. Science 277: 1262-1267.

Lodmell, J.S., Gutell, R.R., and Dahlberg, A.E. 1995. Genetic and comparative analyses reveal an alternative secondary structure in the region of nt 912 of Escherichia coli 16S rRNA. Proc. Natl. Acad. Sci. 92: $10555-10559$.

Masquida, B., Felden, B., and Westhof, E. 1997. Context dependent RNA-RNA recognition in a three-dimensional model of the $16 \mathrm{~S}$ rRNA core. Bioorg. Med. Chem. 5: 1021-1035.

Ogle, J.M., Brodersen, D.E., Clemons Jr., W.M., Tarry, M.J., Carter, A.P., and Ramakrishnan, V. 2001. Recognition of cognate transfer RNA by the 30S ribosomal subunit. Science 292: 897-902.

Ogle, J.M., Murphy, F.V., Tarry, M.J., and Ramakrishnan, V. 2002. Selection of tRNA by the ribosome requires a transition from an open to a closed form. Cell 111: 721-732.

Ogle, J.M., Carter, A.P., and Ramakrishnan, V. 2003. Insights into the decoding mechanism from recent ribosome structures. Trends Biochem. Sci. 28: 259-266.

Powers, T. and Noller, H.F. 1990. Dominant lethal mutations in a conserved loop in 16S rRNA. Proc. Natl. Acad. Sci. 87: 1042-1046.

Recht, M.I. and Puglisi, J.D. 2001. Aminoglycoside resistance with homogeneous and heterogeneous populations of antibiotic-resis- tant ribosomes. Antimicrob. Agents Chemother. 45: 2414-2419.

Rosendahl, G., Hansen, L.H., and Douthwaite, S. 1995. Pseudoknot in domain II of $23 \mathrm{~S}$ rRNA is essential for ribosome function. J. Mol. Biol. 249: 59-68.

Schluenzen, F., Tocilj, A., Zarivach, R., Harms, J., Gluehmann, M., Janell, D., Bashan, A., Bartels, H., Agmon, I., Franceschi, F., et al. 2000. Structure of functionally activated small ribosomal subunit at 3.3 angstroms resolution. Cell 102: 615-623.

Sigmund, C.D., Ettayebi, M., and Morgan, E.A. 1984. Antibiotic resistance mutations in $16 \mathrm{~S}$ and $23 \mathrm{~S}$ ribosomal RNA genes of Escherichia coli. Nucleic Acids Res. 12: 4653-4663.

Sigmund, C.D., Ettayebi, M., Borden, A., and Morgan, E.A. 1988. Methods Enzymol. 164: 673-690.

Spirin, A.S. 2002. Ribosome as a molecular machine. FEBS Lett. 514: $2-10$.

Tama, F., Valle, M., Frank, J., and Brooks 3rd, C.L. 2003. Dynamic reorganization of the functionally active ribosome explored by normal mode analysis and cryo-electron microscopy. Proc. Natl. Acad. Sci. 100: 9319-9323.

Triman, K., Becker, E., Dammel, C., Katz, J., Mori, H., Douthwaite, S., Yapijakis, C., Yoast, S., and Noller, H.F. 1989. Isolation of temperature-sensitive mutants of $16 \mathrm{~S}$ rRNA in Escherichia coli. J. Mol. Biol. 209: 645-653.

Valle, M., Sengupta, J., Swami, N.K., Grassucci, R.A., Burkhardt, N., Nierhaus, K.H., Agrawal, R.K., and Frank, J. 2002. Cryo-EM reveals an active role for aminoacyl-tRNA in the accommodation process. EMBO J. 21: 3557-3567.

Valle, M., Zavialov, A., Sengupta, J., Rawat, U., Ehrenberg, M., and Frank, J. 2003. Locking and unlocking of ribosomal motions. Cell 114: 123-134.

VanLoock, M.S., Agrawal, R.K., Gabashvili, I.S., Qi, L., Frank, J., and Harvey, S.C. 2000. Movement of the decoding region of the $16 \mathrm{~S}$ ribosomal RNA accompanies tRNA translocation. J. Mol. Biol. 304: 507-515.

Velichutina, I.V., Dresios, J., Hong, J.Y., Li, C., Mankin, A., Synetos, D., and Liebman, S.W. 2000. Mutations in helix 27 of the yeast Saccharomyces cerevisiae $18 \mathrm{~S}$ rRNA affect the function of the decoding center of the ribosome. RNA 6: 1174-1184.

Vila-Sanjurjo, A., Squires, C.L., and Dahlberg, A.E. 1999. Isolation of kasugamycin resistant mutants in the $16 \mathrm{~S}$ ribosomal RNA of Escherichia coli. J. Mol. Biol. 293: 1-8.

Vila-Sanjurjo, A., Ridgeway, W.K., Seymaner, V., Zhang, W., Santoso, S., Yu, K., and Doudna-Cate, J.H. 2003. X-ray crystal structures of the WT and a hyper-accurate ribosome from Escherichia coli. Proc. Natl. Acad. Sci.. 100: 8682-8687.

Wimberly, B.T., Brodersen, D.E., Clemons Jr., W.M., Morgan-Warren, R.J., Carter, A.P., Vonrhein, C., Hartsch, T., and Ramakrishnan, V. 2000. Structure of the $30 \mathrm{~S}$ ribosomal subunit. Nature 407: 327-339.

Wriggers, W., Agrawal, R.K., Drew, D.L., McCammon, A., and Frank, J. 2000. Domain motions of EF-G bound to the 70 S ribosome: Insights from a hand-shaking between multi-resolution structures. Biophys J. 79: 1670-1678.

Yusupov, M.M., Yusupova, G.Z., Baucom, A., Lieberman, K., Earnest, T.N., Cate, J.H., and Noller, H.F. 2001. Crystal structure of the ribosome at 5.5 A resolution. Science 292: 883-896. 

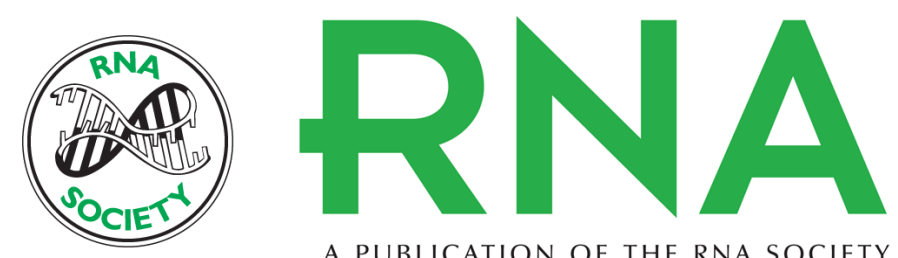

A PUBLICATION OF THE RNA SOCIETY

\section{Genetic evidence against the 16S ribosomal RNA helix 27 conformational switch model}

DANIEL RODRIGUEZ-CORREA and ALBERT E. DAHLBERG

RNA 2004 10: 28-33

References This article cites 37 articles, 12 of which can be accessed free at: http://rnajournal.cshlp.org/content/10/1/28.full.html\#ref-list-1

\section{License}

Email Alerting Service

Receive free email alerts when new articles cite this article - sign up in the box at the top right corner of the article or click here. 